\title{
LOYALTY PROGRAMS IN TOURISM - HOW INFLUENCERS AND COMMUNITIES CHANGE WORD-OF-MOUTH MARKETING
}

\author{
Jacqueline Fäs ${ }^{1}$ and Darius Zumstein ${ }^{2}$ \\ ${ }^{1}$ Lucerne University of Applied Sciences, Zentralstrasse 9, 6002 Lucerne, Switzerland \\ ${ }^{2}$ Zurich University of Applied Sciences, Stadthausstrasse 14, 8400 Winterthur, Switzerland
}

\begin{abstract}
Conventional loyalty programs in the hotel industry often are outdated and should adapt to the digital age. This research shows that common loyalty programs have negative connotations, because hotel guests are inundated with them and the immediate benefits are not noticeable from the customers' point of view. A sustainable loyalty program ideally offers playful incentives so that guests do not lose interest in it. Research found that many guests like to be part of an exclusive online community, where loyalty programs should be based on. Building a community, it is important that all stakeholders can derive added value and do not feel exploited. Moreover, empirical results show that hotel guests expect personalized incentives and offers. To provide these, tourism companies should cooperate with third-party partners. Communities on digital platforms like Instagram or Facebook can generate new guests by word of mouth, short eWOM. Experiences show that recommendations are made when expectations are exceeded: To increase this effect, incentives are still seen to be meaningful, but the nature and (digital) communication channels are changing. Social incentives, such as exclusive events, services or personal guest care, are clearly preferred instead of monetary incentives. It is also human interaction that binds guests to a hotel, which cannot be compensated by monetary incentives only. When guests are individually and immediately rewarded and when their expectations are met, word-of-mouth on social media lead to new customers. Moreover, research indicates that guests often act as micro-influencers on social media and ratings platforms. If they are convinced and find "instagrammable moments", they intrinsically report about a hotel and their services on social media. To recommend a hotel to friends, most guests do not expect anything in return, because they want to be credible and authentic.
\end{abstract}

\section{KEYWORDS}

Loyalty Programs, E-Tourism, Influencer Marketing, Online Marketing, Community Marketing, Hospitality

\section{INTRODUCTION}

A loyalty program aims to bind customers to a company and retain them for the long term. To achieve this, they must offer the company a certain (monetary) incentive to participate. Important is that the customer feels a sense of appreciation (Lewis 2004, p. 286). Loyalty programs are also widespread in the hotel industry. These offer the possibility to treat the customer individually according to his value for the company (Peppers \& Rogers 2004, p. 22).

Research showed that economic incentives, especially in hotels, often lead to a new booking because people are afraid that they otherwise might lose their reward. However, a real connection with the hotel could be proven especially with social incentives (Melancon et al. 2011, p. 343f).

In addition, social media and influencer marketing have seldom been integrated into loyalty programs so far. Influencers, in particular, can no longer be neglected as a new instrument of the marketing mix. Especially among younger target groups, YouTuber and Instagrammer are authentic opinion leaders. In social media like Instagram, Twitter and YouTube, influencers now have more reach than conventional media (Kohn 2016, p. 52). There is no doubt that social media are responsible for a brand and its loyalty (Oracle 2018, p. 7).

The Swiss SV Hotel AG is aware of this problem and would therefore like to use its own hotel brand «Stay KooooK» to launch a new kind of loyalty program. The new hotel brand «Stay KooooK» aims to combine the best out of Airbnb, Hotel, Microliving and Hostel. The idea of this new concept is to convince customers with a place where you feel like home without missing any advantages a hotel would offer. 
This paper therefore clarifies the following main research question: What kind of loyalty program hotels like «Stay KooooK» can launch to maximize the loyalty of its guests? Since the main research question is complex, the research project was divided it into following seven sub research questions:

1. When is a hotel guest called loyal?

2. What are satisfied guests willing to invest in a hotel brand like «Stay KooooK»?

3. What motivates hotel guests to recommend the brand?

4. What would hotels, such as the SV Hotel group, invest in loyalty programs and loyal guests?

5. What do guests expect from a modern hotel for their loyalty?

6. What have be considered when implementing a contemporary loyalty program?

7. How can the loyalty program be used for social media marketing and customer acquisition?

In order to answer these research questions, first current literature was analysed. This secondary research of the project showed that the topics of long-term stays and digital loyalty programs in the hotel industry are rather unexplored fields of research. To close this gap, eleven guideline-based interviews were conducted in spring 2019. The second chapter shows the results from primary and secondary research. The third chapter discusses the synthesis of these results before the fourth chapter ends up with a conclusion and an outlook.

\section{DIGITAL LOYALTY PROGRAMS IN THE HOTEL INDUSTRY}

The underlying research project followed a qualitative research approach. In fact, little research on long-term travellers and the possibility of new loyalty programs was carried out in the hotel industry. For this purpose, an inductive, explorative cross-sectional study was conducted. This included eleven guideline-supported interviews, which were evaluated by topic for each interview group. The respondents consisted of two female and two male hotel guests, three internal experts from SV Hotel group and four external, neutral experts from the hotel industry and social media marketing. In order to compare the results on an aggregated, general level, the transcribed results were summarised in text form as individual case analyses.

\subsection{Basics of Digital Marketing in the Hotel Industry}

The literature research has shown that the topics relevant to the present work were mainly discussed in the English literature. Various general studies on customer retention and loyalty were analyzed. However, the research concentrates primarily on loyalty programs with an ecological and social incentive for customers.

New research results on loyalty programs show that non-monetary incentives have to be taken into account (Fehr \& Falk 2002, p. 688). Social incentives, such as belonging to a community or signalling a social status, are just as attractive as monetary ones (Fehr \& Falk 2002, p. 706). The issue of so called instant rewards is also gaining in importance and is seen as necessary to gaining attention and trust in today's fast-paced world (Tahal 2014, p. 7). Word-of-mouth (WOM) and customers' recommendation of a product or service still is regarded as the highest sign of customer loyalty (Ryue \& Feick 2017, p. 84).

Furthermore, literature shows that approaches of gamification are changing user behaviour (Thorpe \& Roper 2019, p. 601). Since the intention of gamification is not always comprehensible for customers in business practice, it is important to ensure that no moral principles are violated. Recent studies also show that the formation of digital ecosystems or communities can be useful in building a brand, i.e. brand awareness, brand image and brand value (Scheer 2016, p. 281).

Conventional instruments from online marketing are also suited to increase customer loyalty and retention in the hotel industry. Social media marketing, influencer marketing and booking platforms are gaining in importance (Casaló et al. 2017; Conrady \& Buck 2012). Facebook and Instagram enjoy the highest popularity among social media channels in the hotel industry (Oracle 2018). Particularly Instagram became important, because user engagement is higher than in other social medias due to emotional and activating photos (picture-superiority-effect, see Chen \& Yuan 2018). Influencer Marketing like Instagram Marketing has become an important instrument of digital marketing for industries like tourism (Djafarova \& Rushworth 2017). 


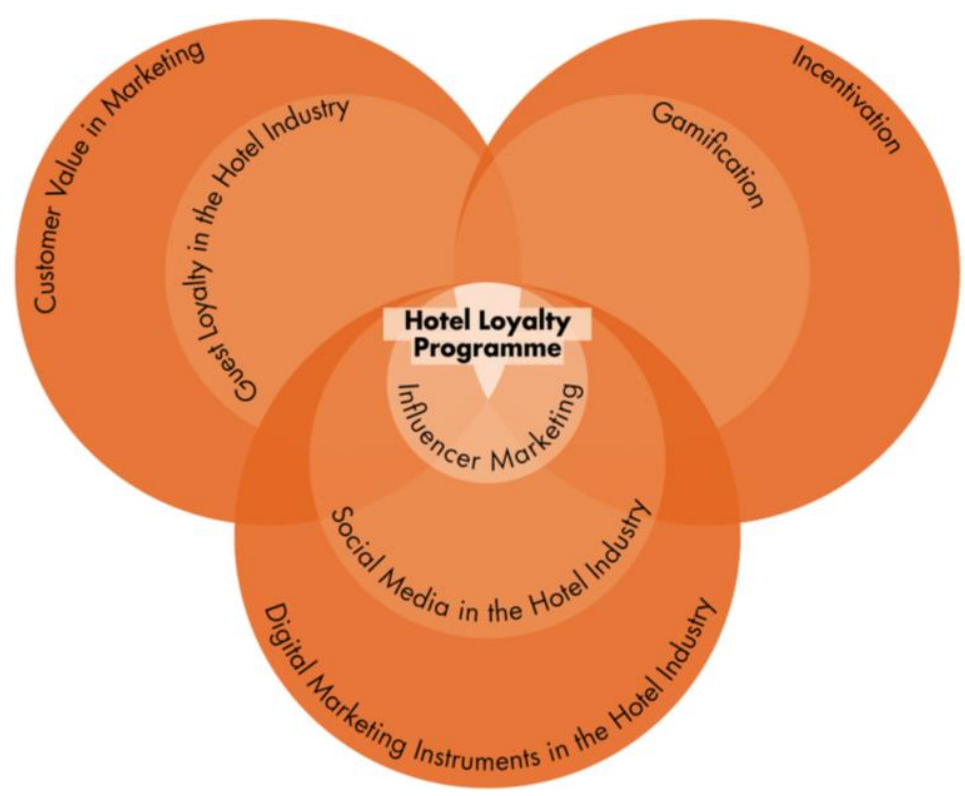

Figure 1. Theoretical Classification of this Paper

However, it does not matter how large the reach or the number of an influencer is. It is important that these are regarded as trustworthy and authentic by the guests (Gupta et al. 2017; Seiler \& Kucza 2017).

Particularly young generations trust more in influencers than in conventional media and in advertising (De Veirman et al., 2017; Kohn 2016). Since social media usage is still growing, it is important to monitor them systematically and strategically. If a hotel knows its reputation on social media platforms and acts actively with its guests, this can be a competitive advantage, or an unique selling proposition (USP), respectively.

\subsection{Needs and Motivation of Long-term Guests}

In the methodical approach of the research project, the transcripts of the conducted interviews were evaluated by a topic analysis. An inductive coding method was chosen, in which following eight codes were developed.

The first code «social media» shows that the (potential) guests are mainly active on Instagram, which corresponds to literature and to the assessments of the experts.

Code 2 «content» and code 3 «influenced action» was found among potential guests. They indicate that they generate contributions in social media about their spare time and reference to companies. They state that they are influenced in their actions by content on social media and that they feel that their content also inspires and influences friends. This confirms the experts' statement that social media platforms are increasingly used as source of inspiration. Code 4 dealt with «influencers». The experts recommend that targeted influencers and micro-influencers should be used to reach potential guests. This opinion was confirmed by the target group.

In code 5 «loyalty program», guests, internal and external experts agreed that it is time to introduce a new approach to the market. The new program should be easy to use, ideally connected to various companies or partners and approach the guest in a differentiated and personal way. This should also be reflected in «rewards» (code 6). Guests indicate that they prefer social incentives. This assessment was also confirmed by the interviews of tourism experts. In addition, they recommend giving guests an advance of trust through instant rewards and providing exclusive incentives to improve the guest experience.

In terms of «loyalty» (code 7), potential guests want their expectations to be exceeded and personal contact with them to be maintained. For experts, loyalty is reflected in an added value for the business, which they specify in the form of a booking, although alternatives hotel offers would be cheaper.

The eighth and last code dealt with the «community idea». It turned out that potential guests like to be part of a community as long as they can extract personal added value. The experts are also aware of this, because in their opinion a community only works if it offers attractive content and exclusive advantages. From their point of view, networking with external partners, guests, local people and employees is a promising idea. This is also the opinion of the external experts: they see a community as an opportunity for a hotel to network locally and to offer guests exclusive advantages. However, the development of a community should not be underestimated. 


\section{DIGITAL LOYALTY PROGRAMS IN THE HOTEL INDUSTRY}

\subsection{Loyal Guest}

In theory, a customer is described as loyal if he buys a product or service more often and is therefore economically valuable for a company. Customers who recommend a product to their environment, such as to friends or family, are also referred to be loyal.

In the hotel business one could go one step further. Hotel guests who return to a hotel thanks to economic incentives are often described as loyal. However, various studies have shown that this is not loyalty only on which a hotel should aim for in the long run. The hotel industry should focus on guests who return because of a good experience they have had with the hotel. A good customer experience often base on human factors such as friendly staff or an excellent service. More loyalty should be ascribed to these guests, as the financially incentivised ones will drop out as soon as competitors provides a better offer. This is also the opinion of the experts surveyed. They would describe a guest as loyal if he or she also booked a hotel although the competitors make a better price. Since not all guests can book the same hotel several times, the factor of word-of-mouth propaganda also plays an important role. In this case, however, it would be important that the guests talk positively about the brand after their visit and thus recommend a hotel to friends or acquaintances actively or passively. In their opinion, a guest can also be described as loyal if (s)he talks more positively about the hotel.

The experts of the analysed hotel group are also aware of this problem. In the experts point of view, there are different levels of loyalty: on the one hand, they see a guest as loyal when he returns to the hotel, but also when he extends his stay or recommends the hotel.

To sum up the findings, three levels of loyalty can be defined: The first is when a guest returns to a hotel again and again or extends his stay. Secondly, if he recommends the hotel to friends, family or to acquaintances in any way and thirdly, if he books the hotel, even if competitors makes cheaper offers. Depending on corporate objectives, these three levels of loyalty can and should be weighted differently.

\subsection{Willingness of Guests to Invest into a Brand}

If the interviewed (potential) guests are convinced of hotel and it's services, they are ready to invest in the hotel brand in following three areas.

- First, hotel guests are active on social media and regularly report on their travels, excursions, experiences with friends about interesting buildings, hotel rooms or objects and (digital) services. They like to link their contributions to official company accounts or mark the location where they are. They advertise a company, a location or a product to their friends without being paid for it. The interviewed guests all say that they do not expect to be paid, because they see social media as a platform of inspiration and for them it is enough to be inspired by contributions from their friends and followers for new services, places or products.

- Second, they have all indicated that they would like to recommend hotels or restaurants to their friends and family if they are completely satisfied with a service or were positively surprised during their hotel stay. This statement is also confirmed by the theory that customers recommend something on their own as soon as a company regularly exceeds their expectations. In order to know exactly what customer's expectations are, a company should understand its customers and regularly ask them about their expectations.

- The third point mentioned by guests is the sense of community and being part of a community. Everyone could imagine that they are involved in a community. Offering yoga lessons in a hotel in their place of residence, guiding guests through their hometown or passing on insider tips are possible examples.

In summary, loyal hotel guests are willing to recommend a hotel to their friends and acquaintances, report on it on their social media channels like Facebook or Instagram and/or they get involved in a community.

\subsection{Guests Motivation for Recommendation}

As mentioned above, the interviews with the guests and the theory show that they are prepared to recommend a brand as soon as their expectations are exceeded. It is not easy to define how these expectations can generally be met or exceeded, as this is a very individual view and each guest has different expectations based on past experiences or recommendations from friends. In the opinion of the experts, hotel staff plays an important role in the recommendation. For example, if the receptionist remembers in the evening that a guest had to leave 
early for a meeting and asks how things went in the evening, this can contribute a lot to the positive experience. Ideally, the hotel may be also provide this guest with a free drink or a spa voucher.

Other factors for exceeding expectations can be a rooftop bar, a new digital service, or a generally appealing location that looks good on Instagram. According to the experts, so-called instagrammable moments, i.e. subjects that are well suited for Instagram, should be generated by hotels and touristic organisations.

The interviewed guests also indicated that they recommend a brand if it offers exclusive access to events or networks. They also appreciate it when they can look behind the scenes of a hotel or when a hotel provides individualised welcome gifts.

Finally, guests are willing to recommend the brand as soon as it either offers them attractive content for their social media channels or in some way exceeds their expectations of a hotel.

\subsection{Incentives from Hotels}

The interviews with the internal experts of the hotel group clearly showed that hotels are willing to give social and monetary incentives to their guests. Launching a loyalty program, hotel groups want to be generous, even if there is often no fixed budget available. According to the respondents, most of the hotels are willing to pay monetary incentives such as discounts, develop an exclusive product line with an external partner, or they offer free cancellation. They could also imagine working with partners if they could make a more attractive offer available to the guests. So far, most hotels often have not yet considered this.

\subsection{Guests' Expectations for their Loyalty}

Based on the results of primary and secondary research, the answer to the question about guests' expectations can be divided into two following parts.

1. When it comes to loyalty, which is measured by recommendations, guests often do not expect anything. On the contrary, especially when it comes to content on social media channels, guests, experts and theory agree that caution must be exercised. As soon as it is known that guests are rewarded for contributions in their private profiles, these are quickly considered more implausible and bought, which can have negative effects on a brand.

2. When it comes to loyalty, which is measured by trust, for example when a guest often returns to a hotel, extends her/his stay or is part of a community, guests clearly expect personal added value. This can take the form of discounts, the possibility of free cancellation or invitations to exclusive events. According to experts, theory and potential guests interviewed, it is important that the guests see personal added value and that the incentive is either individually tailored or can be determined by the guest himself. Another aspect are surprises. The guests surveyed stated that they appreciated it most when they received something from the hotel that they had not expected. These can be small gifts in the room or discount codes tailored to them for third parties they receive during their stay.

Finally, it can be said that hotel guests often do not expect anything directly for their loyalty, but only become loyal if the experience is great, if the service is right, if the staff takes care about the individual needs of their guests and/or if their expectations during their stay are exceeded in some way. This can take the form of personalised monetary or social incentives.

\subsection{Implementation of a Loyalty Program}

The theory and interviews showed that loyalty programs should take into account various factors. It is important that the program is attractive for all of the guest. It may be worthwhile if a loyalty program is not defined or labelled as such, as loyalty programs are often stored in a drawer per se and the user tends to compare them.

One possibility would be to build a community. If one offers exclusive advantages to the members and binds them to the brand, these are ideally also on the side of the company in the case of negative reporting and defend it. For branding and marketing, a well-functioning community is also important. This would also bring a certain flexibility, if a hotel (group) want to integrate partners.

Potential customers as well as experts believe that future loyalty programs would be more attractive if they provided by several brands. If different, complemental companies cooperative, they can provide higher and more differentiated incentives. When it comes to incentives, it is important to divide them into monetary and 
social incentives, which should be preferred for sustainable loyalty. Instant rewards can be used to give customers an edge of trust on their first visit or to exceed their expectations. It is important that guests' expectations can be exceeded. However, according to the theory and interviews results this is not always easy. Hotels have to know and understand its guests and ask them for feedback continuously.

Moreover, it makes sense to integrate gamification elements into the loyalty program, as these motivate users and customers to be a part of it. For example, there might be different statuses that can be achieved and depending on the status, new, previously unknown incentives will be activated. It is important that incentives are personally attractive for the guest. An individualisation should be aimed at.

Finally, the program should be easy to use. This includes, among other things, a user-friendly and visually attractive user interface that is optimised for mobile devices as smartphones or tablets. It can be considered that customers can register directly with a social media profile. Online ratings and reviews written by customers can also be shared again or commented on, which is well received by potential and new guests. It is not decisive whether the contributions are negative or positive. A hotel should pay particular attention to ratings and rewiews on booking platforms like Trip Advisor, Booking.com, Hotels.com, eBookers.com, Expedia.com, etc.

According to the expert interviews, Instagram, Facebook and ratings on booking platforms are considered the most important sources of information and inspiration before booking. The experts also mention LinkedIn as a social media channel that will become increasingly important for companies in the future. The interviewed guests use LinkedIn primarily for professional purposes. Even though in academic research no study could be found describing a positive effect of LinkedIn in the hotel industry, the channel should not be ignored.

For a successful implementation of a (community-based) loyalty program it is important that hotels know what is reported and discussed about them in the social media and that they actively participate in the discourse. The program must be continuously adapted to the current needs of guests to be successful in the long term.

\subsection{Benefits of a Loyalty Program for Customer Acquisition}

Interviews with internal and external experts and theory show that a loyalty program can basically be used in five ways to win customers.

- Firstly, new customers can be won by integrating third parties. If a hotel joins forces with partners, their customers become aware of the hotel and ideally book it if required or recommend it to their community.

- Secondly, new customers can be acquired indirectly by referring existing guests to social media. If a guest is part of the loyalty program and thus receives an individual value added, she or he is likely to mention it on social media in form of a review or rating on his private social media channels. Informed or inspired by these platforms, new customers can be acquired. In this case, guests would act as micro-influencers.

- Thirdly, new guests can be won if an existing guest is completely satisfied with his stay and therefore actively recommends the hotel to others.

- Fourthly, an incentive could be created in the loyalty program if new guests are brought in. A new kind of recommendation program should be combined with a loyalty program. With this mechanism, the hotel would specifically seek to reward guests who acquire new guests. However, care must always be taken to ensure that the measure does not appear chummy or untrustworthy. The mechanism should be designed that loyal guests can be won and not the other ones, who only participate because of the incentive.

- Fifthly, a loyalty program can lead to new guests if it is well received and its possibilities are so exclusive and appealing that new guests become aware of it on their own. They will book a hotel so that they can also be part of this program or community.

\subsection{Development of New Loyalty Programs}

Based on the findings of the partial research questions, the main research question was "what kind of loyalty program can a hotel launch to maximise the loyalty of its guests?". From the interviews with potential guests and experts, it emerged that the guests are above all loyal and therefore recommend the brand to others when they are addressed personally and individually. Therefore, it is important to develop a loyalty program that rewards the guests individuality. In doing so, the loyalty program should contain a wide range of rewards so that members can either choose from them or be rewarded in a personalised way by the hotel with the help of collected data. As discussed above, it makes sense to work together with selected third-party partners in the 
loyalty program. When choosing a partner, it is important that the product or service is suitable for the hotel guest and that he or she regards it as added value.

When launching a new loyalty program, it should also be noted that it is not advertised as such, but that the community idea is in the foreground. The loyalty program should be based on the fact that everyone, whether the hotel, the guests or third party partners, derive added value from it and they are equal. No member should feel exploited or discriminated at any time. Members should be aware that their data will be collected and used for marketing purposes, but in turn they will be rewarded with exclusive incentives.

Furthermore, the incentives should be designed in such a way that they are also suitable (instagrammable) for social media contributions. If guests report positively about their stay, this also inspires new guests to book the hotel. Guests could then act as micro-influencers.

The program should also have a playful character so that it does not become unattractive, boring or forgotten at some point. The guests should remain motivated to be an active part of the community even after their stay in the hotel. It is important that the guests feel that they are part of the hotel community and that the associated loyalty program or incentives for the guests are of secondary importance.

To achieve this, personal contact is essential. It should be done absolutely without the fact that the program is only dealt with online. Exclusive offline events as well as employees who personally look after and advise the guests are indispensable for success or for winning loyal guests.

In summary, it can be said that hotels should come on to the market with a new loyalty program which is not perceived as such, so that no comparisons are made. Especially at the beginning, when a hotel is not yet too well known, credible third-party partners should be involved and the recommendation of the guests and community members should be put on.

\subsection{Case Study «Stay KooooK»}

Based on the knowledge from the research questions an implementation concept for «Stay KooooK» could be developed, which contains differentiated and practical approaches. In a first step, incentives were defined that «Stay KooooK» guests would like from a hotel. These were divided into the categories «Gastronomy», «Local Nightlife», «Co-Working Spaces», «Exclusive Products», «Beauty\&Spa», «Sports», «Music», «Locomotion», «Exclusive Events», «Stay KooooK Incentives» and «Social Engagement». In each case, concrete partners for the first «Stay KooooK» in Bern (Switzerland) were proposed. In addition, three types of mechanism were developed a «KooooKer community». In the first type, the members are given incentives tailored to their status. In the second type, all incentives are visible to all community members and can be purchased with so-called «KooooK-credits». In the third type, the status achieved within the community is regarded as an incentive. Various incentives are distributed or raffled directly to all members.

\section{CONCLUSION}

Answering the main research question, it became clear that hotels should launch a future loyalty program, which is not defined as such, but focuses on the community idea. Each member of this community should receive an individual incentive and should not be exploited at any time. To ensure that the hotels can provide enough attractive incentives, they should cooperate with third-party partners. However, the focus when choosing a partner should clearly be on the needs of the guests. Ultimately, the main goal of a hotel community should be that its guests behave loyally and ideally bring new guests.

The goal of the program could be that it becomes a part of the everyday life of the community and does not fall into oblivion. This aspect can be helped with playful elements. Nevertheless, the focus should always be that the guests want to be part of this community, as membership offers them exclusive advantages. The personal contact should not be forgotten, exclusive events as well as personal guest support are at the top of the guests' wish list. The aim is to positively surprise the guests and exceed their expectations, because this mechanism ultimately leads to the desired word-of-mouth propaganda, which generates new guests.

Literature review and empirical research showed that customer value and guest loyalty have been a major issue in marketing for a long time. However, it was interesting to note that there is hard to find literature in the hotel industry and tourism. It seems that this is a field of research that enjoys great interest. 
Nevertheless, few scientific studies could be found that investigated how a loyalty program in the hotel industry, or in tourism in general, should be designed in the future. Moreover, only limited literature on long-term travellers could be found. In order to close these gaps, it was the right approach to carry out qualitative research in addition to literature research.

Thanks to the survey of potential guests, internal experts of a hotel group as well as external experts from the hotel industry and social media marketing, new insights could be gained which were valuable for answering the research questions. The findings from the interviews partly confirmed previously researched theories, but at the same time introduced new perspectives. Topics such as incentives and gamification have also arisen, which have already been dealt with in secondary research. It was thus confirmed that a future loyalty program in the hotel industry must function across the board and combine disciplines from psychology and online marketing. Based on these new findings, an innovative concept for the first Stay KooooK Hotel in Switzerland was developed and will be implemented in business practice. Since new loyalty program and community concepts have to be tested in business practice, their success and the added value of the present research for practice can only be assumed and has to assessed at a later point. However, since all the experts surveyed showed huge interest in being informed about the results later on, it can be assumed that the research hit the nerve of time, discovered a research gap and partly contributed to closing it.

In summary, it can be said that a hotel must come onto the market with a new loyalty programme, which is not perceived as such, so that no comparison is made. Especially in the case of new brands, credible third-party partners should be consulted at the outset and the recommendation of guests and community members should be the key. However, this explorative, qualitative and practice-oriented research approach of the underlying project is not representative. Therefore, quantitative research should investigate the topics discussed in this paper, by survey a large number of marketing managers in the touristic sector. The different findings and hypotheses of this paper have to be tested on a quantitative level. In future, new and innovative models of loyalty programs of community and influencer marketing have to be developed.

\section{REFERENCES}

Casaló, L. V., Flavián, C., \& Ibáñez-Sánchez, S. (2017). Antecedents of consumer intention to follow and recommend an Instagram account. In: Online Information Review, Vol. 41, Iss. 7, pp. 1046-1063.

Chen, L., Yuan, S. (2018): Influencer Marketing: How Message Value and Credibility Affect Consumer Trust of Branded Content on Social Media, In: Journal of Interactive Advertising, Vol. 19, Is. 1, pp. 58-73.

Conrady, R., Buck, M. (2012). Trends and Issues in Global Tourism 2012, Berlin, Springer.

De Veirman, M., Cauberghe, V., \& Hudders, L. (2017). Marketing through Instagram influencer: Impact of number of followers and product divergence on brand attitude. Ghent University, Belgium.

Djafarova, E., Rushworth, C. (2017). Exploring the credibility of online celebrities' Instagram profiles in influencing the purchase decisions of young female users. In: Computers in Human Behavior, Vol. 68, pp. 1-7.

Fehr, E., Falk, A. (2002). Psychologica foundations of incentives. In: European Economic Review, Vol. 46, Is. 4-5, pp. 687-724.

Gupta, R., Kishor, N., Verma, D. (2017). Construction and Validation of five-dimensional celebrity endorsement scale: Introducing the PATER Model. In: British Journal of Marketing Studies, Vol. 5, Is. 4, pp. 15-35.

Lewis, M. (2004). The influence of loyalty programs and shortterm promotions on customer retention. In: Journal of Marketing Research, Vol. 41, August, pp. 281-292.

Melancon, J., Noble, S., Noble, C. (2011). Managing rewards to enhance relational worth. In: Journal of the Academy of Marketing Science, Vol., 39, Is. 3, pp. 341-362.

Oracle (2018). The Loyalty Divide. Redwood Shores, California, USA.

Peppers, D., Rogers, M. (2004). Managing Customer Relationships: A Strategic Framework. Hoboken, New Jersey.

Ryu, G., Feick, L. (2007). A Penny for Your Thoughts: Referral Reward Programs and Referral Likelihood. In: Journal of Marketing Vol. 71, Is. 1, pp. 84-94.

Tahal, R. (2014). Loyalty Programs in E-Commerce and their perception by the young adult internet population. Central European Business Review Vol.3, Is. 2, pp. 7-13.

Thorpe, A., Roper, S. (2019). The Ethics of Gamification in a Marketing Context. In: Journal of Business Ethics, Vol. 155, pp. 597-609.

Scheer, A. (2016). Value Driver of Digitalisation (in German). In: Informatik Spektrum; Vol. 39, Is. 4, pp. 275-289.

Seiler, R., Kucza, G. (2017). Source Credibility Model, Source Attractiveness Model and Match-up-Hypothesis An Integrated Model. In: Journal of International Scientific Publications, Vol. 11, pp. 1-15. 